\title{
Responses of Soil Microbial Communities to Robinia Pseudoacacia Plantations of Different Ages in A Loess Area
}

\author{
Bingxue Zhang ${ }^{1}$, Rumeng Zhao ${ }^{1}$, Boyuan $\mathrm{Bi}^{1}$, Fengpeng Han ${ }^{1,2, *}$ \\ 1 College of Resources and Environment, Northwest A\&F University, Yangling, Shaanxi 712100, China; \\ 2 State Key Laboratory of Soil Erosion and Dryland Farming on the Loess Plateau, Northwest A\&F University, Yangling, Shaanxi \\ 712100 , China \\ * Correspondence: hanfp@ms.iswc.ac.cn
}

\begin{abstract}
Phospholipid fatty acids (PLFAs) can be used as biomarkers for qualitative and quantitative analyses of soil microbial community diversity. In this study, we collected soil samples at 10-cm intervals to a depth of $1 \mathrm{~m}$ from Robinia pseudoacacia plantations of four different ages (10, 15, 25 and 40 years) in a loess area and analysed the soil microbial community structure by PLFA analysis. A total of 97 PLFAs were detected in soils of $R$. pseudoacacia plantations of different ages. The individual PLFA contents gradually decreased in the 0 - to $40-\mathrm{cm}$ soil layers, with little variation in the $40-$ to $100-\mathrm{cm}$ soil layers. The individual PLFAs were similarly distributed in the soils of $R$. pseudoacacia plantations of different ages, and there was a clear variation with stand age and soil depth. The individual PLFA contents in the $0-$ to $20-\mathrm{cm}$ soil layers were highest for the 25-year-old plantation, while those in the 20 - to $40-\mathrm{cm}$ soil layers were relatively high for the 25 - and 40-year-old plantations; the 16:0 content was the highest among individual PLFAs. The total PLFA content and the PLFA contents of different microbial groups [bacteria, fungi, Gram-positive bacteria $\left(\mathrm{G}^{+}\right)$, Gram-negative bacteria $\left(\mathrm{G}^{-}\right)$and actinomycetes] initially increased before decreasing in the soils of $R$. pseudoacacia plantations with increasing stand age, whereas these contents gradually decreased with increasing soil depth; the highest PLFA contents was found in the 25-year-old plantation. The total PLFA content and the contents of fungal, $\mathrm{G}^{-}$and actinomycete PLFAs in the soils of $R$. pseudoacacia plantations differed significantly among stands of different ages in the $0-$ to $10-\mathrm{cm}, 10-$ to $20-\mathrm{cm}$ and $30-$ to $40-\mathrm{cm}$ soil layers, while no significant differences were found in the 20- to $30-\mathrm{cm}$ soil layers; the $\mathrm{G}^{+}$and bacterial PLFAs contents in each of the 0 - to 40 -cm soil layers were significantly different. The PLFA ratios between different microbial groups differed among the stands of different ages. The fungi/bacteria ratio showed a "decrease-increase-decrease" trend with stand age, while the $\mathrm{G}^{+} / \mathrm{G}^{-}$ratio showed an "increase-decrease" trend. The saturated/monounsaturated PLFA ratio initially decreased before plateauing, while the opposite trend was observed for the cyclopropyl/precursor ratio. The PLFA contents of different microbial groups were ranked as follows: bacteria $>\mathrm{G}^{-}>\mathrm{G}^{+}>$

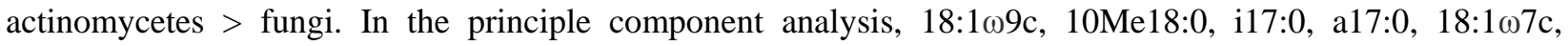
$18: 1 \omega 5 \mathrm{c}$ and 18:0 made the greatest contribution to principal component 1 , and a14:0, i14:0 3OH, i14:0, i14:1 $17 \mathrm{c}$ and 14:0 made the greatest contribution to principal component 2. In conclusion, soil nutrient status and other soil eco-environmental stress factors should be considered in 10- to 25-year-old (particularly $\sim 15$-year-old) plots for the management of $R$. pseudoacacia plantations to prevent forest soil degradation and improve forest stand quality, thereby achieving better soil and water conservation and environmental improvement in R. pseudoacacia plantations.
\end{abstract}

Keywords: soil; Robinia pseudoacacia; PLFA; stand age; microbial community

\section{Introduction}

Soil microbes are one of the most active soil constituents, with a decisive influence on the vegetation-soil ecosystem. They actively participate in energy flow, nutrient cycling and organic matter transformation in the 
soil, and they play a major role in maintaining ecosystem structure and function [1]. Variations in many soil microbial indicators, such as soil microbial biomass, enzyme activity, community structure and functional diversity, can reflect the health of the soil ecosystem [2]. In particular, the soil microbial community structure and diversity can reflect relatively early variations in soil environmental quality and reveal differences in the ecological functions of microbes; hence, soil microbes are considered important biological indicators [3,4]. The soil microbial community structure is influenced by the soil, climate and environmental factors (e.g., pH, soil moisture, temperature conditions, nutrient contents and availability) [5-8]. Additionally, vegetation is a major influential factor, mainly due to differences in the environment created by plants for microbes, the properties of food provided by plants (e.g., litter) and the chemical composition of root exudates [9,10]. The majority of soil microbes are difficult to culture, making the study of microbial community structures difficult [11]. In recent years, attempts have been made to overcome this difficulty using phospholipid fatty acid (PLFA) analysis [12,13], BIOLOG-ECO analysis [14] and molecular biological methods [15]. However, the BIOLOG method is not suitable for analysing the entire microbial community structure, and the success of molecular biological methods depends on the physiological state of the microbes in the environment. The PLFA analysis can be used to detect microbial community changes in the samples and is less affected by microbial physiology. The main principle of PLFA analysis is that the PLFA composition and content of various microbes show species specificity, which can be used to directly estimate microbial biomass and community structure [16]. Forest ecosystems with different stand ages show substantial differences in nutrient cycling and energy flow. Varying intensities of plant-soil interactions can result in differences in the environment and biological constitution of forest soils. Moreover, soil water and nutrient conditions as well as oxygen concentrations vary with depth, which also influences the microbial biomass and community structure. Therefore, studies examining the characteristics of the microbial community structure at different soil depths with different stand ages have great implications for our understanding of soil environmental conditions and quality.

Black locust (Robinia pseudoacacia Linn.) is characterised by tolerance to drought and barren soil, a developed root system, rapid growth and a high yield. Thus, $R$. pseudoacacia has become one of the major types of plantations for vegetation restoration in semi-arid and sub-humid areas of the Loess Plateau $[17,18]$. Over the past few decades, $R$. pseudoacacia plantations have been extensively constructed in large areas of this region. $R$. pseudoacacia has also been widely planted in Yan'an, which plays a major role in improving the eco-environment and preventing soil and water loss in this region, even regulating the hydrological conditions in the Yellow River Basin [19]. Robinia pseudoacacia, which originates in the Appalachian Mountains of North America, has been introduced and cultivated in China. This tree is most common in North China and the Yellow River Basin, with the best growth documented at 400-1200 m above sea level in North China [20]. The construction of $R$. pseudoacacia plantations uses mainly pure stands, while local species slowly invade during the late growth stage. The tree layer comprises Acer stenolobum, Pyrus betulaefolia, Populus davidiana and Ulmus pumila L.; the shrub layer comprises Syringa oblata Lindl., Cotoneaster acutifolius Turcz., Rosa hugonis Hemsl. and Rhamnus erythroxylon Pall.; and the herb layer comprises Artemisia gmelinii, Artemisia giraldii Pamp., Stipa bungeana Trin., Bothriochloa ischaemum (L.) Keng, Cirsium setosum (Willd.) MB. and Plantago depressa Willd. [21]. In recent years, numerous studies have been conducted to examine $R$. pseudoacacia plantations in terms of reasonable planting density, intensity of thinning improvement, species diversity and biomass [19,22-27]. However, few studies have investigated differences in microbial biomass and microbial community structure between stands of different ages. In the present study, we selected 10-, 15-, 25and 40-year-old $R$. pseudoacacia plantations and used PLFA analysis to investigate changes in soil microbial biomass and community structure under the near-natural management of $R$. pseudoacacia plantations. This study provides a theoretical reference for the long-term sustainable management of $R$. pseudoacacia 
plantations.

\section{Materials and Methods}

\subsection{Study Area}

The study area is located in the urban and suburban areas of Baota District, Yan'an City, Shaanxi Province, China. This area is part of the hilly-gully region of the Loess Plateau, lying at the geographic location of $36^{\circ} 24^{\prime}-38^{\circ} 47^{\prime} \mathrm{N}$ and $109^{\circ} 28^{\prime}-110^{\circ} 22^{\prime} \mathrm{E}$, with an average elevation of $987.4 \mathrm{~m}$ above sea level. The area has a continental monsoon climate in the temperate zone. There are four distinct seasons, with rain and heat over the same period. The average annual rainfall is $550 \mathrm{~mm}$, the annual frost-free period lasts 170 days, and the annual average temperature ranges from $7.7-10.6^{\circ} \mathrm{C}$. The vegetation in the study area consists of deciduous broad-leaved forests in the warm temperate zone. Owing to the serious destruction of the original vegetation, this area has experienced serious soil and water losses. Plantations including mainly $R$. pseudoacacia, Platycladus orientalis (L.) Franco and Pinus tabuliformis Carrière have been planted for many years to rebuild and restore healthy forest ecosystems. The major soil type is loessial soil, containing 63-73\% silt and 17-20\% clay. The soil has a loose texture and poor resistance to erosion and scouring, with serious soil and water loss.

\subsection{Sample Collection and Processing}

We selected 10-, 15-, 25- and 40-year-old $R$. pseudoacacia plantations with a relatively consistent slope $\left(30^{\circ}\right.$ and $35^{\circ}$ ) and aspect (shaded slope) among other site conditions to form a chronosequence of $R$. pseudoacacia plantations. Soil samples were collected in June 2016. Four sampling points were selected at 5-m intervals from the upper to the lower slope in plantations of each age. Soils were collected using a soil auger at each point to a depth of $1 \mathrm{~m}$, and one sample was obtained every $10 \mathrm{~cm}$. A total of 160 soil samples were obtained.

In the field, the soil samples were placed in sealed bags and stored in a cooler box with periodic replacement of the ice packs. The samples were transported to the laboratory, immediately freeze-dried and stored in a $-70^{\circ} \mathrm{C}$ refrigerator for PLFA analysis.

\subsection{Sample Determination and Analysis}

Soil microbial PLFAs were extracted following the modified Bligh-Dyer method [28,29], using esterified $\mathrm{C} 19: 0$ as the internal standard. The extraction, purification and analytical determination procedures were as follows. A 5-g soil sample was oscillated with a mixture of chloroform:methanol:citric acid buffer (volume ratio $=1: 2: 0.8)$ to extract the total lipids. The obtained PLFAs were separated on an SPE silica gel column (CNWBOND Si SPE Cartridge, 500mg, 3ml; Art Number: 2.CA1353.0001). After alkaline esterification, the PLFA composition was analysed using an Agilent $7890 \mathrm{~N}$ gas chromatographer. The PLFA profile was obtained for statistical analysis of the types and quantities of soil microbes. The chromatographic conditions were as follows: HP-5 capillary column $(25 \mathrm{~m} \times 200 \mu \mathrm{m} \times 0.33 \mu \mathrm{m})$; sample volume, $2 \mu \mathrm{l}$; split ratio, 100:1; carrier gas, $\mathrm{H}_{2}\left(2 \mathrm{ml} \cdot \mathrm{min}^{-1}\right)$; makeup gas $\left(30 \mathrm{ml} \cdot \mathrm{min}^{-1}\right)$. The content of the PLFA fractions was analysed using the MIDI Sherlock Microbial Identification System (MIDI, Inc., Newark, DE, USA).

\subsection{Naming and Calculation of Soil PLFAs}

In this study, we used the method reported by Frostegård [30] with the formula (i/a/cyc)X: Y $\omega Z(\mathrm{c} / \mathrm{t})$, where " $\mathrm{X}$ " is the number of carbon atoms in the main chain, " $Y$ " is the number of unsaturated olefinic bonds, " $\omega$ " is the distance between the olefinic bond and the carboxyl group, " $\mathrm{Z}$ " is the position of the olefinic bond or cyclopropane chain, " $\mathrm{i}$ " is the isomeric methyl branch, "a" is the former isomeric methyl branch, "cyc" is the 
cyclopropyl group, and suffixes "c" and " $\mathrm{t}$ " are cis and trans isomers, respectively. "Me" denotes methyl branches. In general, saturated PLFAs were calculated as the sum of 12:0, 13:0, 14:0, 16:0 and 18:0; monounsaturated PLFAs were calculated as the sum of $16: 12 \mathrm{OH}, 16: 1 \omega 5 \mathrm{c}$ and cy17:0. Isomeric PLFAs were calculated as the sum of i14:0, i15:0, i16:0 and i17:0; trans-isomeric PLFAs were calculated as the sum of a15:0 and a17:0. Cyclopropyl PLFAs were calculated as the sum of cy 17:0 and cy 19:0; precursor PLFAs were

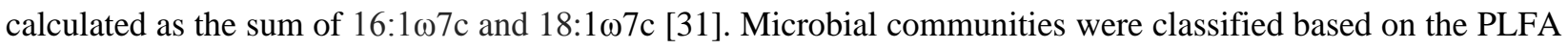
biomarkers listed in Table 1 [32-35]. The PLFA content was calculated for bacteria, fungi, actinomycetes, Gram-positive $\left(\mathrm{G}^{+}\right)$bacteria and Gram-negative $\left(\mathrm{G}^{-}\right)$bacteria.

The contents of total and individual PLFAs were calculated based on the molar amount of the internal standard C19:0. The absolute content of PLFAs $\left(C / \mathrm{nmol} \cdot \mathrm{g}^{-1}\right)$ was calculated as follows: $C=A_{i} m_{s} /(A s \cdot m)$, where $A_{i}$ is the peak area of the $i$-th PLFA fraction, $A_{s}$ is the peak area of the internal standard, $m_{s}$ is the mass of the internal standard, and $m$ is the mass of the soil sample. The relative percentage of PLFAs was obtained as the percentage of the peak area of the $i$-th PLFA to the total peak area.

Table 1. PLFA biomarker for calculating the soil microbial biomass

\begin{tabular}{ll}
\hline \multicolumn{1}{c}{ Microbe type } & PLFA biomarker \\
\hline Bacteria & $12: 0,13: 0,14: 0, \mathrm{a} 14: 0, \mathrm{i} 14: 0,15: 0, \mathrm{i} 15: 0, \mathrm{a} 15: 0,16: 0, \mathrm{a} 16: 0, \mathrm{i} 16: 0, \mathrm{i} 17: 0,16: 1 \omega 5 \mathrm{c}, 16: 1 \omega 7 \mathrm{c}, \mathrm{cy} 17: 0, \mathrm{a} 17: 0,18: 0$, \\
& $\mathrm{i} 19: 0, \mathrm{cy} 19: 0,20: 0$ \\
Actinomycetes & $10 \mathrm{Me} 16: 0,10 \mathrm{Me} 17: 1 \omega 7 \mathrm{c}, 10 \mathrm{Me} 18: 1 \omega 7 \mathrm{c}, 10 \mathrm{Me} 18: 0,10 \mathrm{Me} 20: 0$ \\
$\mathrm{G}^{+}$ & $\mathrm{i} 14: 0, \mathrm{i} 15: 0, \mathrm{a} 15: 0, \mathrm{i} 16: 0, \mathrm{a} 16: 0, \mathrm{i} 17: 0, \mathrm{a} 17: 0, \mathrm{i} 18: 0$ \\
$\mathrm{G}^{-}$ & $16: 1 \omega 5 \mathrm{c}, 16: 1 \omega 7 \mathrm{c}, 16: 1 \omega 9 \mathrm{c}, 17: 1 \omega 8 \mathrm{c}, 18: 1 \omega 5 \mathrm{c}, 18: 1 \omega 7 \mathrm{c}, \mathrm{cy} 17: 0, \mathrm{cy} 19: 0$ \\
Fungi & $16: 1 \omega 5 \mathrm{c}, 18: 2 \omega 6 \mathrm{c}, 18: 2 \omega 9 \mathrm{c}, 18: 1 \omega 9 \mathrm{c}$ \\
\hline
\end{tabular}

\subsection{Data Processing}

Data processing, statistical analyses and mapping were performed using Excel 2007 and SPSS 20. The difference between different data sets was evaluated using one-way analysis of variance (ANOVA) and the least significant differences (LSD) test. The raw data for PLFAs were subjected to principal component analysis (PCA).

\section{Results}

\subsection{Variation Trends in Microbial PLFA Content with Depth in Soils of R. Pseudoacacia Plantations of} Different Ages

The microbial PLFAs content showed distinct variation trends with depth in soils of $R$. pseudoacacia plantations of different ages. Fig. 1 shows the trends in the contents of 10 individual PLFAs with relatively high levels in the 1-m soil profile. In the soil layers above $40 \mathrm{~cm}$, the content of individual PLFAs markedly decreased with increasing depth for $R$. pseudoacacia plots of different ages. In the soil layers below $40 \mathrm{~cm}$, the variation trend in the content of individual PLFAs tended to be minimal. Thus, we focused on the analysis of variations in PLFA content within the 0- to 40-cm soil layers in the following sections. 


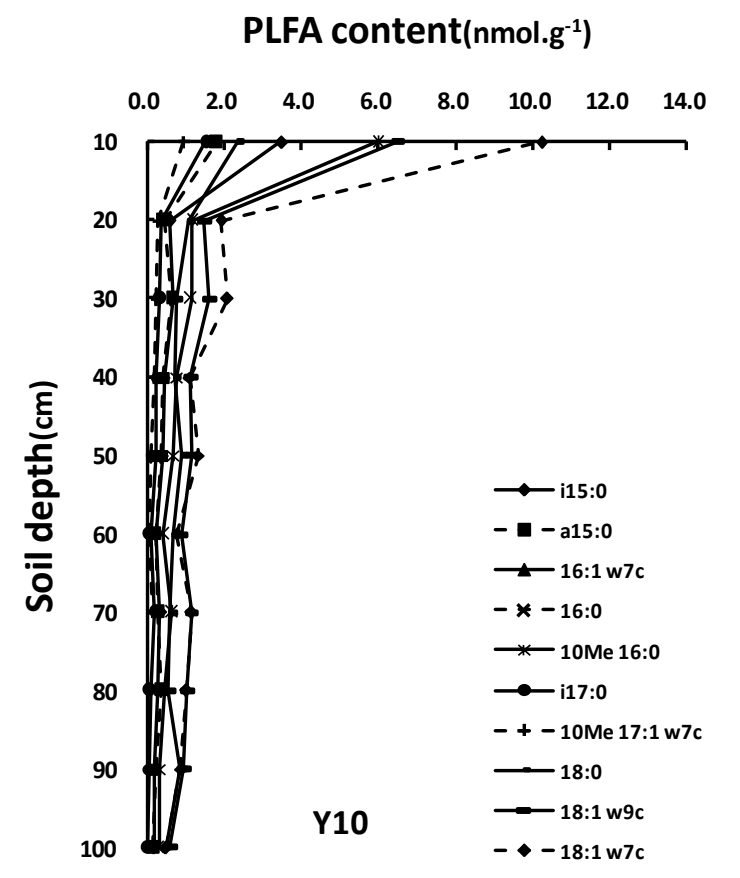

PLFA content(nmol. $\left.\mathrm{g}^{-1}\right)$
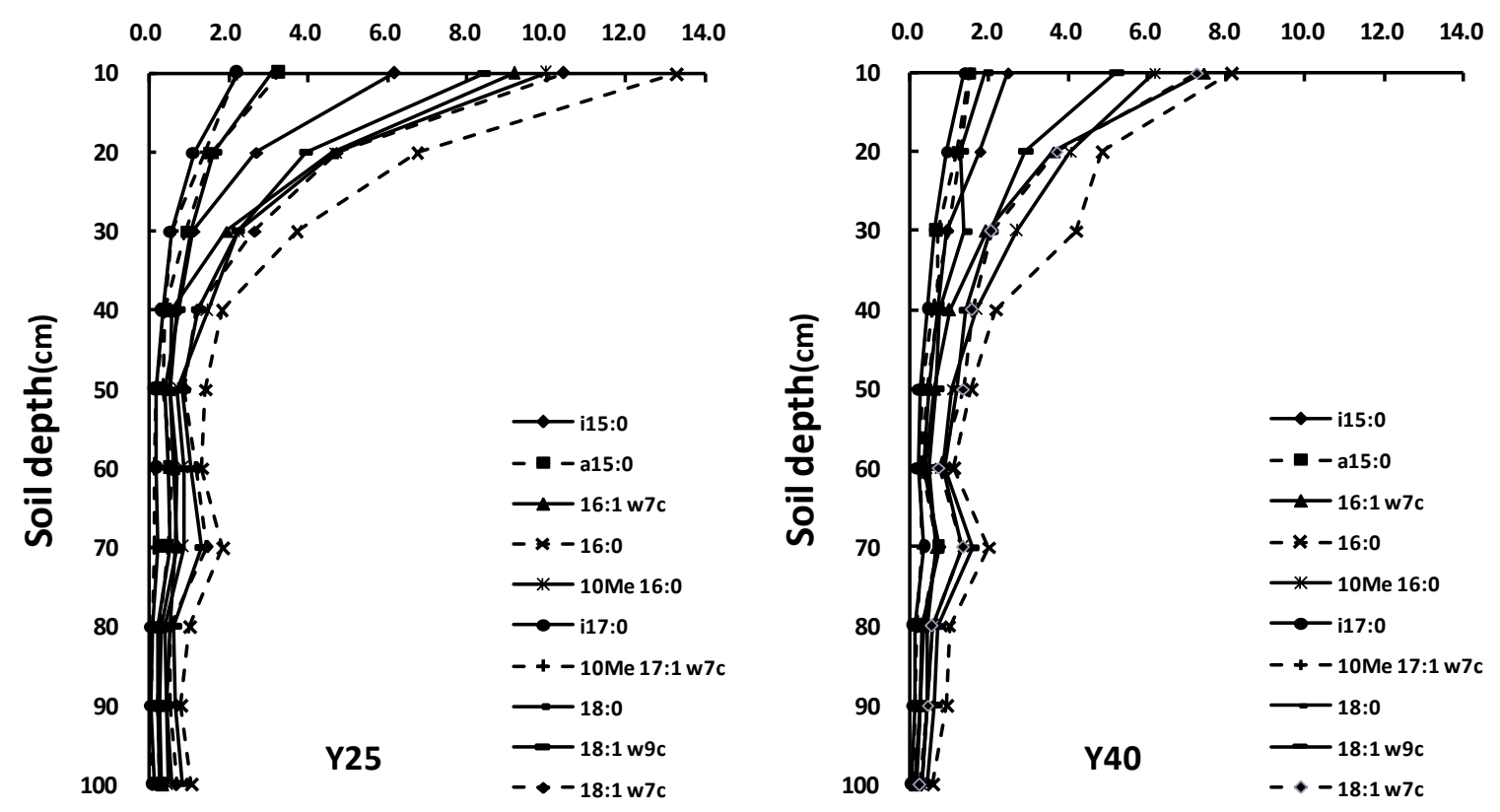

Fig. 1. Soil PLFA content profiles of Robinia pseudoacacia plantations of different ages

Note: Y10, Y15, Y25 and Y40 denote 10-, 15-, 25- and 40-year-old $R$. pseudoacacia plantations, respectively

\subsection{Microbial PLFA Composition in Soils of R. Pseudoacacia Plantations of Different Ages}

A total of 97 PLFAs were detected in soils of R. pseudoacacia plantations of different depths and ages. Specifically, 77, 72, 83 and 85 PLFAs were found in soils of the 10-, 15-, 25- and 40-year-old plantations, respectively, including saturated straight fatty acids, saturated branched fatty acids, cyclopropyl fatty acids, monounsaturated fatty acids and polyunsaturated fatty acids. Further analysis of the 28 PLFAs present in the soils of $R$. pseudoacacia plantations at relatively high levels (Fig. 2) revealed similar patterns and variations in PLFA contents; the content of 16:0 was the highest and accounted for 12.76-14.01\% of the total PLFA content. 
Additionally, the $18: 1 \omega 7 \mathrm{c}, 10 \mathrm{Me} 16: 0,16: 1 \omega 7 \mathrm{c}, 18: 1 \omega 9 \mathrm{c}$, cy19:0 and i15:0 contents were relatively high. Variations in the contents of individual PLFAs exhibited a certain regularity. In the 0 - to $20-\mathrm{cm}$ soil layers, the contents of different PLFAs remained the highest for the 25-year-old plantation, while there were no significant differences in the contents of individual PLFAs between the remaining plots of other ages. In the 20- to 40-cm soil layers, the contents of different PLFAs were relatively high for the 25- and 40-year-old plantations. Additionally, Fig. 2 shows that the contents of different PLFAs markedly decreased with increasing soil depth, in agreement with the results shown in Fig. 1.

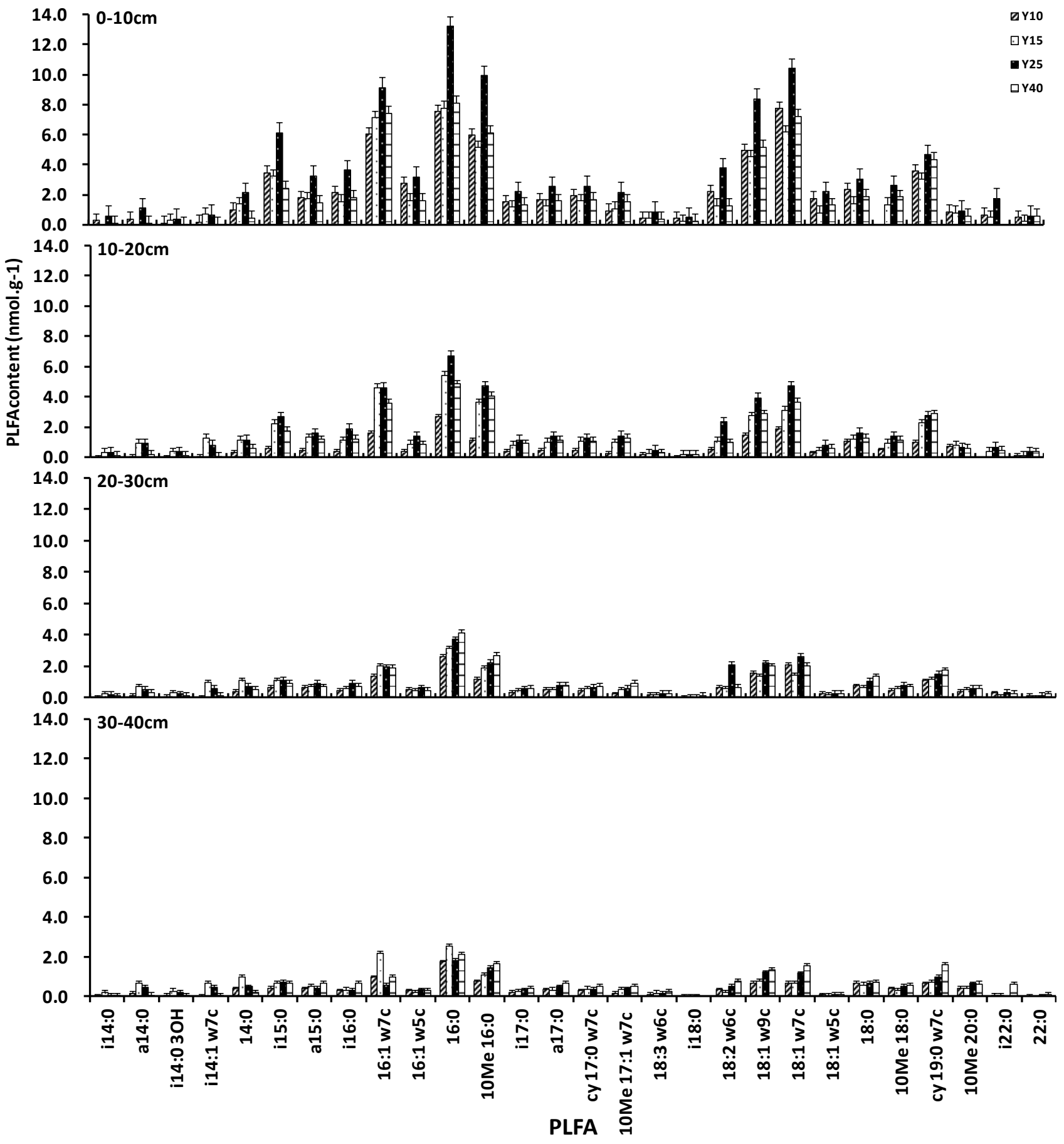

Fig. 2. Distribution of different PLFAs at different soil depths in Robinia pseudoacacia plantations of different ages 


\subsection{PLFA Content of Various Microbial Groups in Soils from R. Pseudoacacia Plantations of Different Ages}

The biomass of various microbial groups and the total microbial biomass in soils of $R$. pseudoacacia plantations showed significant variations among the different stand ages and soil depths (Fig. 3). As shown in Fig. 3a, in the 0- to 10-cm and 10- to 20-cm soil layers, the total PLFA soil contents in the R. pseudoacacia plantations initially increased and then decreased with the stand age, and the highest content was found in the 25-year-old plantation. In the 20- to 30-cm and 30- to 40-cm soil layers, the total PLFA content did not differ significantly in soils among plantations of various ages $(\mathrm{P}>0.05)$. The total PLFA content in soils of all plantations varied with depth: $0-10 \mathrm{~cm}>10-20 \mathrm{~cm}>20-30 \mathrm{~cm}>30-40 \mathrm{~cm}$, in line with the variations in individual PLFA contents with depth. A comparison of Figs. 3b-f with Fig. 3a revealed that the PLFA contents of various microbial groups, including fungi, bacteria, actinomycetes, $\mathrm{G}^{+}$and $\mathrm{G}^{-}$, generally followed the same trends as the total PLFA content in the soils. Based on ANOVA, we found significant differences in total PLFA content as well as the contents of fungal, actinomycete and $\mathrm{G}^{-}$PLFAs among the stands of different ages in the 0 - to $10-\mathrm{cm}, 10$ - to $20-\mathrm{cm}$ and $30-$ to $40-\mathrm{cm}$ soil layers $(\mathrm{P}<0.05)$; however, no significant differences were detected in the 20 - to $30-\mathrm{cm}$ soil layer $(\mathrm{P}>0.05)$. The contents of bacterial and $\mathrm{G}^{+}$PLFAs significantly differed between stand ages in each soil layer $(\mathrm{P}<0.05)$. Additionally, the results showed that the PLFA contents of microbial groups varied in the same soil layer and could be ranked as follows: bacteria $>\mathrm{G}^{-}>\mathrm{G}^{+}>$ actinomycetes $>$ fungi.
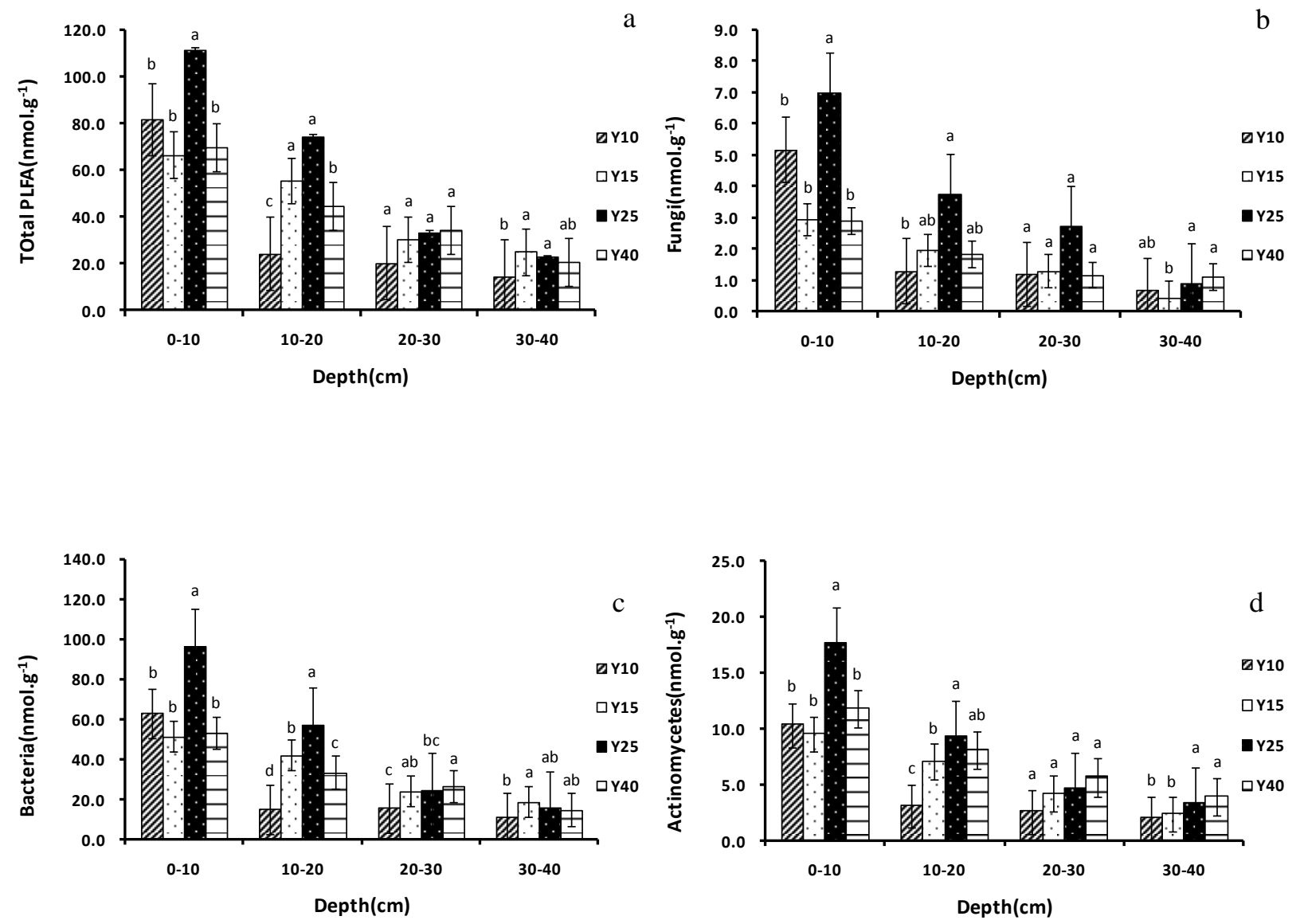

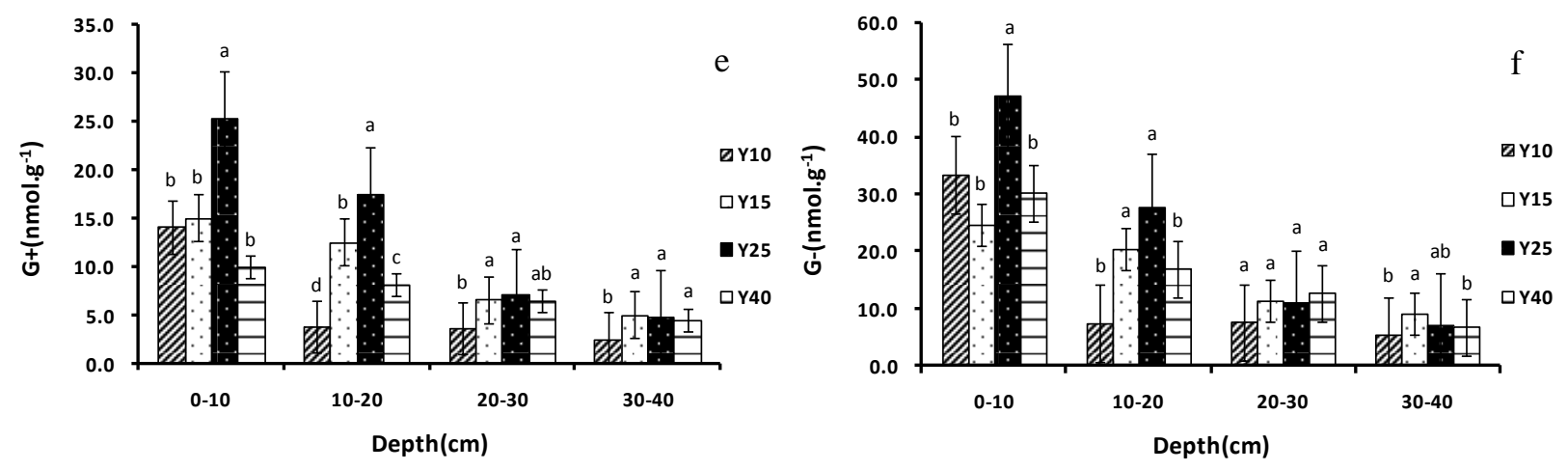

Fig. 3. Microbial PLFA contents in different soil depths in Robinia pseudoacacia plantations of different ages

\subsection{Variations in Microbial Community Structures in Soils of R. Pseudoacacia Plantations}

The microbial PLFA composition in soil reflects the physiological characteristics of the soil microbes. Analyses of the fungi/bacteria (F/B), saturated/monounsaturated PLFA (sat/mono), cyclopropane:precursor PLFAs (cy/pre) and $\mathrm{G}^{+} / \mathrm{G}^{-}$ratios (Fig. 3) showed that the PLFA ratios between different microbial groups exhibited various trends among the stands of different ages, while these trends were subject to slightly different effects of depth. The F/B ratio significantly differed among the stands of various ages $(\mathrm{P}<0.05)$ and showed a "decrease-increase-decrease" trend with stand age; this ratio was relatively high in the 10- and 25-year-old plantations. The sat/mono ratio initially decreased before levelling off with the change in stand age; this ratio was highest in the 10-year-old plantation, with no significant differences among the stands of various ages ( $\mathrm{P}>$ 0.05). The cy/pre ratio followed a trend opposite to that of the sat/mono ratio, with the highest ratio observed in the 40-year-old plantation; no significant differences were observed in the cy/pre ratio between the 10-, 15- and 25-year-old plantations $(\mathrm{P}>0.05)$. The $\mathrm{G}^{+} / \mathrm{G}^{-}$ratio showed an "increase-decrease" trend with stand age; this ratio was highest in the 25 -year-old plantation and lowest in the 10-year-old plantation.
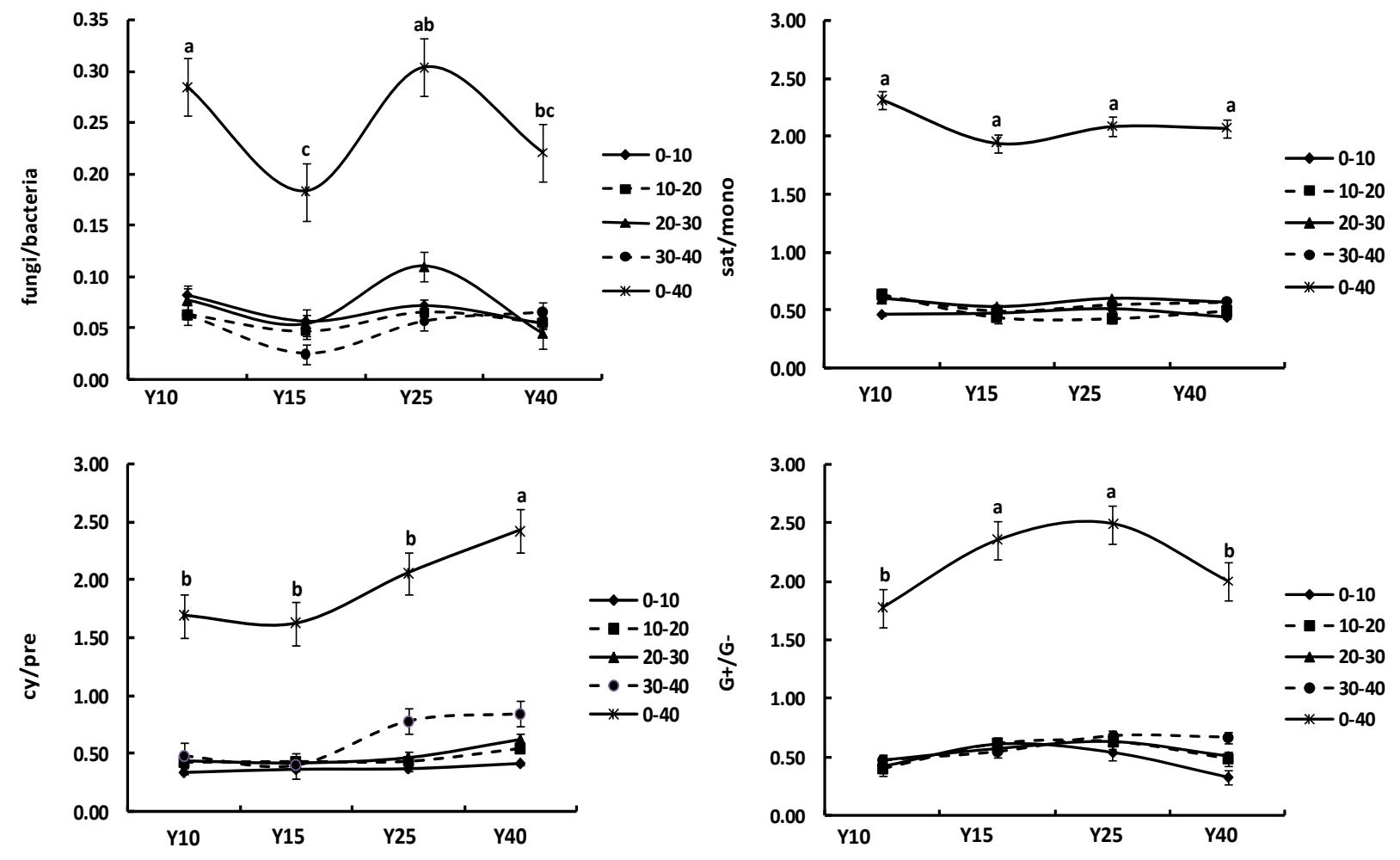

Fig. 4. Ratios among different microbial PLFAs in the soil of Robinia pseudoacacia plantations of different ages 


\subsection{PCA Analysis of Microbial PLFAs in Soils of R. Pseudoacacia Plantations}

PCA analysis was performed on microbial PLFAs in soils of $R$. pseudoacacia plantations of different ages (Fig. 5A). Two principal components (PC1 and PC2) were obtained, which explained $62.35 \%$ and $32.22 \%$ of the total variation in microbial community structure in soils of $R$. pseudoacacia plantations of different ages. The results revealed significant differences between various stand ages $(\mathrm{F}=4.883, \mathrm{P}=0.028)$. The 10 - and 40-year-old $R$. pseudoacacia plantations were influenced mainly by PC2, whereas the 15 - and 25-year-old $R$. pseudoacacia plantations were influenced mainly by PC1.

The eigenvector loadings of different PLFAs on the principal components reflect the relationship between PLFAs and the principal factors; the higher the loading is, the closer is the relationship [36](Sun et al., 2011). The analysis of initial eigenvector loadings of different PLFAs (Table 2) showed that five PLFAs had original eigenvector loadings greater than 0.95 for factor 1 ; four PLFAs had original eigenvector loadings between 0.90 and 0.95 for factor 1; and i17:0 had higher original eigenvector loadings than did the remaining PLFAs. To better explain the relationship between PLFAs and the principal factors, we performed a varimax rotation on the factor matrix (Table 2). For factor 1, 18:1 $\omega 9 \mathrm{c}$ and 10Me18:0 had loadings greater than 0.9, and i17:0, a17:0, 18:1 $17 \mathrm{c}, 18: 1 \omega 5 \mathrm{c}$ and 18:0 had loadings between 0.90 and 0.95; these PLFAs made the greatest contribution to PC1. For factor 2, a14:0 and i14:0 3OH had loadings greater than 0.90, and i14:0, i14:167c and 14:0 had loadings between 0.80 and 0.90 ; these PLFAs made the greatest contribution to PC2. Further analysis of the loading diagram of PLFAs after rotation (Fig. 4B) revealed three PLFAs (a14:0, 14:0 3OH and i14:1 $\omega 7 \mathrm{c}$ ) in the

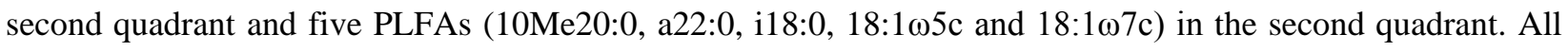
the remaining PLFAs were distributed in the first quadrant. Additionally, a14:0, 14:0 3OH, i14:167c and 10Me20:0 were relatively distant from the PLFA-dense area, indicating a poor correlation between these four PLFAs and other PLFAs.
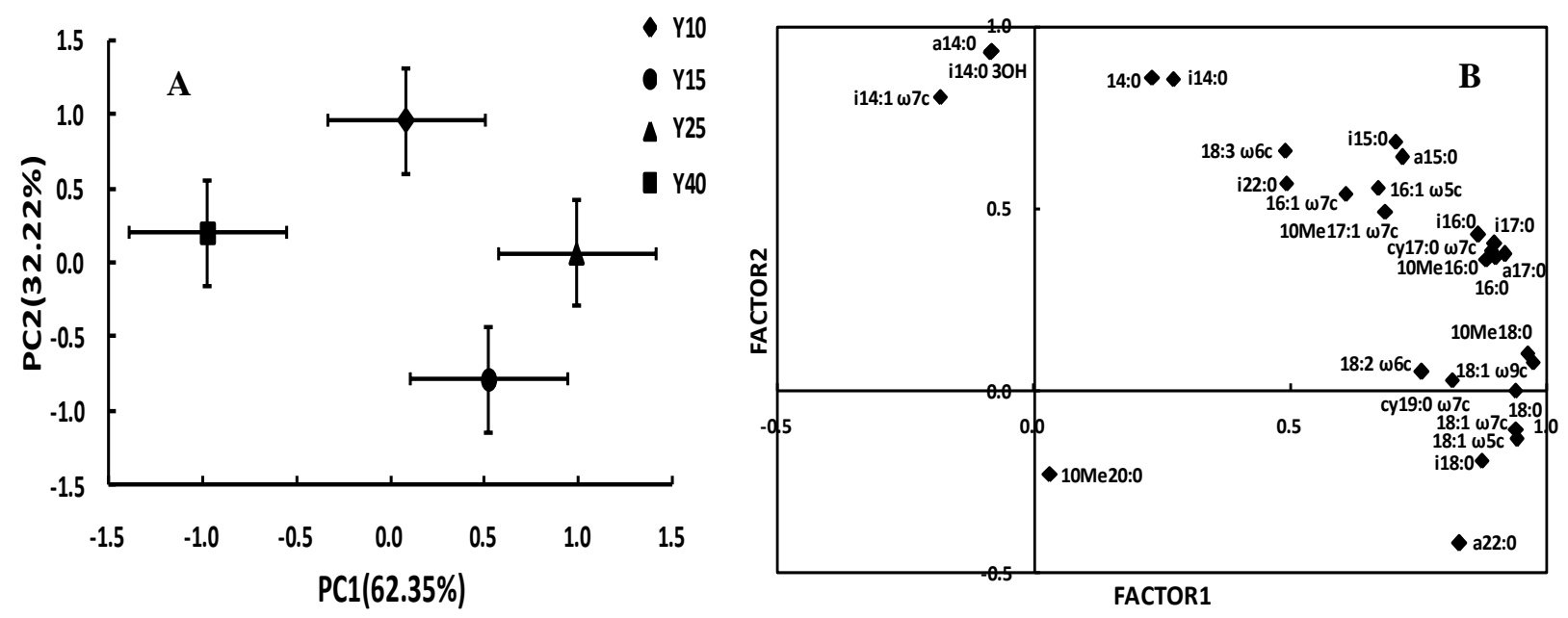

Fig. 5. Principal component analysis (A) and eigenvector loadings (B) of PLFAs in the soil of Robinia pseudoacacia plantations of different ages

Table 2. Eigenvector loadings of different PLFAs in the soil of Robinia pseudoacacia plantations of different ages

\begin{tabular}{|c|c|c|c|c|}
\hline \multirow{2}{*}{ PLFA } & \multicolumn{2}{|c|}{ Original eigenvector loadings } & \multicolumn{2}{|c|}{ Eigenvector loadings after rotation ${ }^{*}$} \\
\hline & Factor 1 & Factor 2 & Factor 1 & Factor 2 \\
\hline i14:0 & 0.602 & 0.666 & 0.271 & 0.856 \\
\hline $\mathrm{i} 14: 03 \mathrm{OH}$ & 0.308 & 0.881 & -0.087 & 0.929 \\
\hline $\mathrm{i} 14: 1 \omega 7 \mathrm{c}$ & 0.169 & 0.810 & -0.183 & 0.807 \\
\hline $14: 0$ & 0.568 & 0.686 & 0.231 & 0.861 \\
\hline
\end{tabular}




\begin{tabular}{|c|c|c|c|c|}
\hline a15:0 & 0.919 & 0.284 & 0.718 & 0.641 \\
\hline $\mathrm{i} 16: 0$ & 0.985 & -0.006 & 0.898 & 0.405 \\
\hline $16: 1 \omega 7 \mathrm{c}$ & 0.778 & 0.239 & 0.608 & 0.541 \\
\hline $16: 1 \omega 5 \mathrm{c}$ & 0.842 & 0.227 & 0.671 & 0.557 \\
\hline $16: 0$ & 0.971 & -0.021 & 0.891 & 0.385 \\
\hline $10 \mathrm{Me} 16: 0$ & 0.966 & 0.029 & 0.867 & 0.429 \\
\hline i17:0 & 0.990 & -0.040 & 0.917 & 0.375 \\
\hline a17:0 & 0.971 & -0.041 & 0.900 & 0.367 \\
\hline cy17:0 $07 \mathrm{c}$ & 0.952 & -0.040 & 0.882 & 0.360 \\
\hline $10 \mathrm{Me} 17: 1 \omega 7 \mathrm{c}$ & 0.827 & 0.162 & 0.685 & 0.491 \\
\hline $18: 3 \omega 6 c$ & 0.719 & 0.398 & 0.489 & 0.661 \\
\hline i18:0 & 0.714 & -0.538 & 0.873 & -0.192 \\
\hline $18: 2 \omega 6 c$ & 0.709 & -0.266 & 0.756 & 0.053 \\
\hline $18: 1 \omega 9 \mathrm{c}$ & 0.917 & -0.334 & 0.973 & 0.078 \\
\hline $18: 1 \omega 7 \mathrm{c}$ & 0.800 & -0.511 & 0.941 & -0.132 \\
\hline $18: 1 \omega 5 \mathrm{c}$ & 0.811 & -0.486 & 0.940 & -0.104 \\
\hline 18:0 & 0.854 & -0.390 & 0.939 & 0.001 \\
\hline 10Me 18:0 & 0.918 & -0.305 & 0.962 & 0105 \\
\hline cy19:0 $07 \mathrm{c}$ & 0.754 & -0.313 & 0.815 & 0.029 \\
\hline 10Me 20:0 & -0.066 & -0.219 & 0.031 & -0.227 \\
\hline i22:0 & 0.685 & 0.312 & 0.493 & 0.569 \\
\hline 22:0 & 0.580 & -0.725 & 0.829 & -0.417 \\
\hline
\end{tabular}

* Varimax rotation.

\section{Discussion}

In the present study, we analysed the soils from R. pseudoacacia plantations of different ages in Yan'an, northern Shaanxi Province. A total of 97 PLFAs were detected, including 77, 72, 83 and 85 PLFAs in the soils of 10-, 15-, 25- and 40-year-old $R$. pseudoacacia plantations. These numbers were slightly higher than the numbers of PLFAs detected by $\mathrm{Hu}$ [37] in soils of single $R$. pseudoacacia plantations on a slope in Yangjuangou, Yan'an (66 PLFAs in the 0- to 10-cm soil layer and 68 PLFAs in the 10- to 20-cm soil layer). On the one hand, the $R$. pseudoacacia plantations examined in the present study included stand ages of 10, 15, 25 and 40 years. Due to the increase in stand age, the succession of vegetation could change, resulting in variations in the soil eco-environment and further influencing the microbial community structure. On the other hand, the soil depth interval tested in the present study was $0-100 \mathrm{~cm}$. With increasing soil depth, the moisture, temperature and oxygen concentrations could change, thus influencing the types and quantities of microbes. Based on the analysis of 10 PLFAs that changed with depth, we found that the content of different PLFAs gradually decreased in the 0 - to $40-\mathrm{cm}$ soil layers, while little difference occurred in the 40- to $100-\mathrm{cm}$ soil layers. Soil microbial communities directly and sensitively reflect the changes in soil biological activity and soil environmental quality [38]. The contents of different PLFAs showed similar structural patterns in the soils of $R$. pseudoacacia plantations of different ages, and dominant PLFAs were distinct. This finding suggests that the structural pattern of individual PLFA contents in soils of $R$. pseudoacacia plantations was influenced mainly by vegetation type. Vegetation type has a significant effect on soil microbial composition and diversity [39]. However, owing to the vegetation-soil interaction, there are inconsistent mechanisms and outcomes for the effect of various factors on soil microbial groups [40]. In the present study, stand age had little effect on the structural pattern of individual PLFA contents in soils of $R$. pseudoacacia plantations; however, the content of individual PLFAs showed obvious variation trends with stand age. In the 0 - to 20 -cm soil layers, the contents of the different PLFAs were highest in the 25-year-old plantation. In the 20- to 40-cm soil layers, the contents of individual PLFAs were relatively high for both the 25- and 40-year-old plantations. The content of 16:0, indicative of bacteria, was highest among various PLFAs, in agreement with the results of most studies, such as those examining Phyllostachys heterocycla [41], Averrhoa carambola L. and Litchi chinensis Sonn. [42]. 
The PLFA content in soil is closely related to microbial biomass and can be used to measure microbial groups and biomass [43]. In the present study, the total PLFA content and the PLFA content of different microbial groups in soils of $R$. pseudoacacia plantations showed a "decrease-increase-decrease" trend with stand age in the 0 - to $20-\mathrm{cm}$ soil layer. This finding is consistent with the results reported by Yang [44]. regarding different years of artificial grassland in the Sanjiangyuan region. At a consistent stand age and soil depth, the PLFA content of different microbial groups can be ranked as follows: bacteria $>\mathrm{G}^{-}>\mathrm{G}^{+}>$ actinomycetes $>$ fungi. With increasing stand age, the relative abundance of fungi compared with bacteria first decreased and then increased, followed by a decrease in the soils of $R$. pseudoacacia plantations. This trend reflects the changes in organic matter content and system stability in soils of $R$. pseudoacacia plantations. The relatively high F/B ratio in soils of the 10- and 25-year-old $R$. pseudoacacia plantations may be associated with soil structure and nutrition status. The sat/mono ratio can indicate the activity level of soil organic matter [45]. In the present study, we found that the sat/mono ratio initially decreased and then increased before plateauing; however, no significant differences were found among the $R$. pseudoacacia plantations of different ages. The cy/pre ratio gradually increased with increasing stand age, indicating that the characteristics of the microbial community structure in soils of $R$. pseudoacacia plantations were influenced by nutrient factors and other environmental factors. It has been reported that water stress [46], heavy metals and organic pollutants [47] can increase the cy/pre ratio.

The microbial community structure revealed differences in the soils of $R$. pseudoacacia plantations of different ages (Fig. 5A). In the PCA analysis, PC1 and PC2 could well explain the variation by $62.35 \%$ and

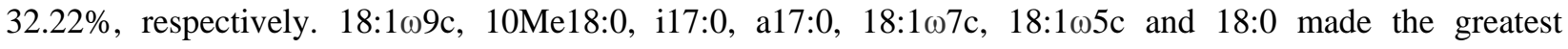
contribution to $\mathrm{PC} 1$, whereas a14:0, i14:0 3OH, i14:0, i14:1 $107 \mathrm{c}$ and 14:0 made the greatest contribution to PC2. Additionally, a14:0, 14:0 3OH, i14:1 $107 \mathrm{c}$ and 10Me20:0 correlated poorly with the remaining PLFAs.

Soil microbes are an important part of forest ecosystems, and microbial community diversity is of great significance to the stability of forest ecosystems. In this study, we analysed by PLFA analysis the variations in microbial community structure with stand age in soils of $R$. pseudoacacia plantations from Yan'an. We found that the PLFA content of different microbial groups initially increased before decreasing with stand age. Both the individual PLFA contents and the PLFA content of the microbial groups reached relatively high or the highest level in the 25-year-old $R$. pseudoacacia plantation. This finding has implications for guiding the reasonable management of $R$. pseudoacacia plantations. During the management of $R$. pseudoacacia plantations, attention should be paid to soil nutrient status and other soil eco-environmental stress factors in 10to 25-year-old (particularly $\sim 15$-year-old) plots to prevent forest soil degradation and improve forest stand quality, thereby achieving better soil and water conservation in $R$. pseudoacacia plantations and improving the environment.

\section{Conclusions}

(1) A total of 97 PLFAs were detected in soils of R. pseudoacacia plantations of different ages in Yan'an. The individual PLFA contents gradually decreased in the 0 - to 40-cm soil layers, with little change in the 40- to $100 \mathrm{~cm}$ soil layers. Individual PLFAs were similarly distributed in the soils of $R$. pseudoacacia plantations with different ages, and the 16:0 content was the highest among the different PLFAs.

(2) The total PLFA content and the PLFA content of the different microbial groups (bacteria, fungi, $\mathrm{G}^{+}, \mathrm{G}^{-}$ and actinomycetes) initially increased and then decreased with increasing stand age, while they gradually decreased with increasing soil depth. The highest contents were observed for the 25-year-old $R$. pseudoacacia plantation. The PLFA ratio between microbial groups showed varying trends among the different stand ages. The F/B ratio showed a "decrease-increase-decrease" trend, while the $\mathrm{G}^{+} / \mathrm{G}^{-}$ratio showed an 
"increase-decrease" trend. The sat/mono ratio initially decreased before plateauing, demonstrating an opposite trend compared with that of the cy/pre ratio. The PLFA content of the different microbial groups can be ranked as follows: bacteria $>\mathrm{G}^{-}>\mathrm{G}^{+}>$actinomycetes $>$fungi.

(3) The content and structure of microbial PLFAs in soils of the 25-year-old $R$. pseudoacacia plantation were significantly different compared with those of $R$. pseudoacacia plantations of other ages. In the PCA,

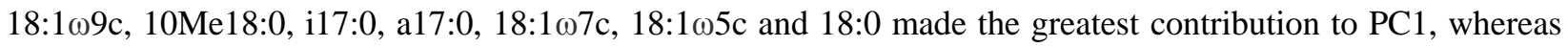
a14:0, i14:0 3OH, i14:0, i14:1 $107 \mathrm{c}$ and 14:0 made the greatest contribution to PC2. Therefore, in the management of $R$. pseudoacacia plantations, soil nutrient status and other soil eco-environmental stress factors should be noted in 10- to 25-year-old (particularly $\sim 15$-year-old) plots to prevent forest soil degradation and improve forest stand quality, thereby achieving better soil and water conservation in $R$. pseudoacacia plantations and improving the environment.

Acknowledgements: This study was supported by the National Natural Science Foundation of China (41471437), CAS "Light of West China" Programme (2016YB04), The National Key Research and Development Programme of China (2016YFA0600801), The Science and Technology Basic Work of China (2014FY210130) and The Basic Research Foundation of the Northwest A\&F University (2014YB059).

\section{References}

1. Zhong W H, Gu T, Wang W., et al. 2010. The effects of mineral fertilizer and organic manure on soil microbial community and diversity[J]. Plant and soil, 326(1):511-522

2. Lerch T Z, Dignac M F, Nunan N, et al. 2009. Dynamics of soil microbial populations involved in 2,4-D biodegradation revealed by FAME-based stable probing[J]. Soil Biology and Biochemistry, 41(1):77-85

3. Wang M C, Liu Y H, Wang Q, et al. 2008. Impacts of methamidophos on the biochemical, catabolic, and genetic characteristics of soil microbial communities[J]. Soil Biology and Biochemistry, 40(3):778-788

4. Alexander K, Bryans T. 2006. Evaluation of the sterility test for detection of microbial contaminants of allografts[J]. Cell and Tissue Banking, 7(1):23-28

5. Kuramae E, Gamper H, Van Veen J, et al. 2011. Soil and plant factors driving the community of soil-borne microorganisms across chronosequences of secondary succession of chalk grasslands with a neutral pH[J]. Fems Microbiology Ecology, 77(2):285-294

6. Drenovsky R E, Vo D, Graham K J, et al. 2004. Soil water content and organic carbon availability are major determinants of soil microbial community composition[J]. Microbial Ecology, 48(3):424-430

7. Bell C, Acosta-Martinez V, Mcintyre N, et al. 2009. Linking microbial community structure and function to seasonal differences in soil moisture and temperature in a Chihuahuan Desert Grassland[J]. Microbial Ecology, 58(4):827-842

8. Islam MR, Trivedi P, Palaniappan P, et al. 2009. Evaluating the effect of fertilizer application on soil microbial community structure in rice based cropping system using fatty acid methyl esters (FAME) analysis[J]. World J Microbial Biotechnol, 25(6):1115-1117

9. Kourtev P S, Ehrenfeld J G, Håggblom M. 2003. Experimental analysis of the effect of exotic and native plant species on the structure and function of soil microbial communities [J]. Soil Biology and Biochemistry, 35: 895-905

10. Ushio M, Balser T, Kitayama K. 2013. Effects of condensed tannins in conifer leaves on the composition and activity of the soil microbial community in a tropical montane forest[J]. Plant Soil, 365: 157-170

11. Zhang H X, Wang X Y, Qi H Y. 2003. Development in research methods of microbial ecology[J]. Acta Ecologica Sinica, 23(5): 988-995

12. Chi P, Wang S P, Jia S G et al. 2011. Effects of three planting patterns on soil microbial community composition[J]. Chinese Journal of Plant Ecology, 35(9): 965-972

13. Syakti A D, Mazzella N, Nerini D, et al. 2006. Phospholipid fatty acid of a marine sedimentary microbial community in a laboratory microcosm: response to petroleum hydrocarbon contamination[J]. Organic Geochemistry, 37(11): 1617-1628

14. Lu S B, Guo X C, Rui Y C, et al. 2012. Utilization of carbon sources by the soil microbial communities of different forest types in subtropical Australia[J]. Acta Ecologica Sinica, 32(9): 2819-2826 
15. Wu C W, Zhao L P. 2011. Technologies on soil Microbiology Diversity[J]. Chinese Agricultural Science Bulletin, 27(11): 231-235

16. Peter Saetre, Erland Bååth. 1999. Spatial variation and patterns of soil microbial community structure in a mixed spruce-birch stand [J]. Soil Biology and Biochemistry, 32(2000): 909-917

17. Li J, Wang X C, Shao M A et al. 2010. Simulation of biomass and soil desiccation of Robinia pseudoacacia forestlands on semi-arid and semi-humid regions of China's Loess Plateau[J]. Chinese Journal of Plant Ecology, 34(3):330-339

18. Shan C J, Liang Z S. 2006. Relationship between root distribution of locust plantation and soil water in the Loess Plateau[J]. Journal of Central South Forestry University, 26(9): 19-21

19. Wang K Q, Wang B R. 2002. Study on thinning to Robinia pseudoacacia forest on the Loess Plateau[J]. Chinese Journal of Applied Ecology, 13(1): 11-15

20. Xiong Y, Tang D R, Wang D X et al. 2013. Understorey species diversity and biomass of artificial Robinia pseudoacacia forests in Yan'an suburb[J]. Journal of Northwest Forestry University, 28(5): 1-7

21. Wang D X, Li G, Hu Y N et al. 2015. Urban Forest Plants and Greening Tree Species in Yan'an[M]. Yangling: Northwest A\&F University Press. 8-10

22. Wang B T, Wang Y, Guo J H et al. 2006. Effect on biomass of stand density of artificial black locust forest in semi-arid region of Loess Plateau[J]. Science of Soil and Water Conservation, 3(3): 35-39

23. Zhang C Q, Zhang W H. 2009. A study on asexual reproduction and regeneration of Robinia pseudoacacia plantations in different habitats in hilly area of the Loess Plateau[J]. Journal of Northwest A\&F University (Natural Science Edition), 37(9): $135-144$

24. Peng H. 2001. Effects of age and site goodness on the growth of black locust (Robinia pseudoacacia L.) and Chinese pine (Pinus tabuliformis Carr.) plantations on the Weibei Loess Plateau[J]. Journal of Northwest Forestry University, 16(3): 1-6

25. Liu J H, Liu G B, Hou X L et al. 2008. Relationship between soil moisture of Robinia pseudoacacia forests and aboveground biomass of understory vegetation[J]. Journal of Soil and Water Conservation, 22(3): 43-46

26. Du F, Cheng J M, Shan L. 2002. Dynamic characteristics of soil moisture under tree, shrub and grass vegetation conditions[J]. Journal of Soil and Water Conservation, 16(1): 91-94

27. Deng L, Zhang W H. 2010. Natural development pattern of Robinia pseudoacacia plantations in loess hilly region [J]. Scientia Silvae Sinicae, 46(12): 15-22

28. Bligh E G, Dyer W J. 1959. A rapid method of total lipid extraction and purification[J]. Canadian Journal of Biochemistry and Physiology, 37(8): 911-917

29. Frostegård A, Tunlid A, Bååth E. 1991. Microbial biomass measured as total lipid phosphate in soils of different organic content[J]. Journal of Microbiological Methods, 14(3): 151-163

30. Frostegård A, Bååth E, Tunlid A. 1993. Shifts in the structure of soil microbial communities in limed forests as revealed by PLFA analysis[J]. Soil Biology and Biochemistry, 25(6):723-730

31. Wu Y P. 2009. Study on soil microbial community structure diversity based on phospholipid fatty acid analysis technique[D]. Zhejiang: Zhejiang University. 47-54

32. Kimura M, Asakawa S. 2006. Comparison of community structures of microbiota at main habitats in rice field ecosystems based on phospholipid fatty acid analysis [J]. Biology Fertility Soils, 43: 20-29

33. Ohansen A, Olsson S. 2005. Using phospholipid fatty acid technique to study short-term effects of the biological control agent Pseudomonas fluorescens DR54 on the microbial microbiota in barely rhizosphere[J]. Microbial Ecology, 49: 272-281

34. Vestal J R, Ehite D C. 1989. Lipid analysis in microbial ecology: quantitative approaches to the study of microbial communities[J]. Bioscience, 39: 535-541

35. Joergensen R G, Potthoff M. 2005. Microbial reaction in activity, biomass and community structure after long-term continuous mixing of a grassland soil [J]. Soil Biology and Biochemistry, 37: 1249-1258

36. Sun D D, Xu Q F, Tian T et al. 2011. Investigation on soil microbial biomass and structure in Phyllostachys edulis plantations with increasing cultivation time[J]. Scientia Silvae Sinicae, 47(7): 181-186

37. Hu C J, Guo L, Liu G H. 2014. Soil microbial community structure under different vegetation restoration patterns in the loess hilly area[J]. Acta Ecologica Sinica, 34(6): 2986-2995

38. Zhao S, Zhang J N, Lai X et al. 2011. Analysis of microbial biomass C, N and soil microbial community structure of Stipa steppes using PLFA at grazing and fenced in Inner Mongolia, China[J]. Journal of Agro-environment Science, 30(6): 1126-1134

39. Jangid K, Williams M A, Franzluebbers A J, et al. 2011. Land-use history has a stronger impact on soil microbial community composition than aboveground vegetation and soil properties[J]. Soil Biology and Biochemistry, 43(10): 2184-2193 
40. Wang M, Qu L Y, Ma K P et al. 2014. Response of soil microbial community composition to vegetation types[J]. Acta Ecologica Sinica, 34(6): 6640-6654

41. Zhang W Y, Sheng K Y, Fan C F et al. 2015. Phospholipid fatty acid analysis of microbial community structure in rhizosphere soil of Phyllostachys edulis in Gannan[J]. Acta Agriculturae Universitatis Jiangxiensis, 37(3): 475-483

42. Ruan C Q, Chen J L, Liu B et al. 2011. Phospholipid fatty acid analysis on the soil microbial communities in the root zones of Averrhoa carambola Linn and Litchi chinensis Sonn.[J]. Chinese Journal of Tropical Crops, 32(10): 1903-1909

43. Bai Z, He H B, Zhang W et al. 2006. PLFA technique and its application in the study of soil microbiology[J]. Acta Ecologica Sinica, 26(7): 2388-2394

44. Yang X Z, Wang C T, Zi H B et al. 2015. Soil microbial community structure characteristics in artificial grassland with different cultivation years in the headwater region of Three Rivers, China[J]. Chinese Journal of Applied \& Environmental Biology, 2015, 21(2): 341-349

45. Bai Z, Zhang Y, Yan Y et al. 2009. Effect of long-term fertilization on activity and community structure of soil microbes in farmland mollisol[J]. Acta Pedologica Sinica, 46(1): 108-116

46. Schutz K, Nagel P, Vetter W, et al. 2009. Flooding forested groundwater recharge areas modifies microbial communities from top soil to groundwater table[J]. FEMS Microbial Ecol, 67(1): 171-182

47. Cordova-Kreylos A L, Cao Y P, Green P G, et al. 2006. Diversity, composition, and geographical distribution of microbial communities in California salt marsh sediments[J]. Applied and Environmental Microbiology, 72(5): 3357-3366 